\title{
Experimental Study on Rotational Behavior of Bolted Glulam Beam-to-column Connections Reinforced Using CFRP Sheets
}

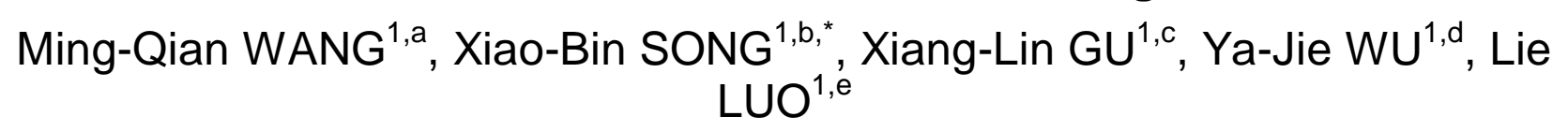

\author{
'Department of Building Engineering, Tongji University, 1239 Siping Road, Shanghai, China \\ a1wangmingqian@tongji.edu.cn, bxiaobins@tongji.edu.cn, ${ }^{c}$ guxianglin@tongji.edu.cn, \\ '9yajie_wu@tongji.edu.cn, 'luolie@tongji.edu.cn \\ *Corresponding author
}

Keywords: Glulam, Bolted Beam-to-column Connection, Slotted-in Steel Plate, CFRP sheet, Monotonic Loading Test, Moment Resistance, Deformability.

\begin{abstract}
In this study, three groups of bolted glulam beam-to-column connections with slotted-in steel plates (in total 11 full-scale specimens) were tested under monotonic loading to investigate the rotational behavior of such connections with the use of carbon fiber reinforcing polymer sheets wrapping. The influence of CFRP sheet layers on the performance improvement of the connections was also quantified. The test results indicated that the maximum moments were increased by $14 \%$ and $18 \%$ for reinforced connections wrapped using 1 and 2 layers of CFRP sheets, respectively; furthermore, the deformability ratios evaluated based on the rotation angles corresponding to the yielding and maximum moments, respectively, were increased by $78 \%$ and $72 \%$. It was also found that the variation of the maximum moment of reinforced connections can be reduced with increased layers of CFRP sheets.
\end{abstract}

\section{Introduction}

Modern timber structure members could be connected using various types of metal fasteners, such as bolts, nails, metal truss plates, and so on. Bolted glulam connections with slotted-in steel plates (hereinafter referred to as bolted glulam connections) have gained increasing attention due to their high efficiency for assembly and excellent durability. But the moment resistance of such connections is low [1]; and, unpredicted splitting and shear plug failures could occur due to the brittle nature of wood under tension and shear.

Many techniques have been used in timber structures to increase the connection moment resistance. Early research efforts were made on using densified materials $[2,3,4]$ or glued-in rods $[5,6]$, but these methods may cost additional curing time. Modern self-tapping screws (STSs) provide an alternative to increase the tension perpendicular-to-wood-grain strength. Lam et al. tested non-reinforced and STS-reinforced connections and found that the improvement of moment resistance and ductility was notable [7]. However, the difficulty of drilling full threaded and large diameter STSs into glulam members may cut down the practical significance. Research on the cross-laminated timber (CLT) technique showed that, connections reinforced using locally cross-laminated glulam (often in the jointing area of the beam members) exhibited excellent rotational deformability, even superior than STS-reinforced connections [8]. But locally CLT technique can only be used in new buildings rather than existing structures.

Recently, fiber reinforcing polymer (FRP) material has been widely used in strengthening reinforced concrete members [9]. Generally, FRP material under tension behaves with high elastic modulus and strength; therefore, wrapping FRP material perpendicular to wood grain could improve timber tensile performance by providing a circumferential confinement. Zhang et al. conducted tests on the longitudinally cracked wood columns reinforced using CFRP sheets and found that CFRP sheets could slow down the splitting and recover the column compression capacity by $20 \%$ [10]. O'Brien carried out double shear loading tests on FRP-reinforced bolted glulam connections and found that reinforced connections achieved higher yielding and ultimate strength [11]. However, these studies did not apply to the rotational behavior of bolted glulam connections. 
To validate the rotational performance improvement of connections wrapped with CFRP sheets, monotonic loading tests were conducted with full-scale bolted glulam connections. A comparison of the CFRP-reinforced specimens with non-reinforced specimens was also carried out to quantify the improvement of moment resistance and deformability.

\section{Materials and Specimen Preparation}

A total of eleven bolted flatwise-laminated glulam beam-to-column connections were produced and tested. All the specimens were broken into two main groups: one was used as the control group (S1) with 5 non-reinforced replicates; the other was used as experimental group with 6 CFRP-reinforced specimens. To study the influence of different layers of CFRP sheets, the experimental group was further divided into two smaller groups: specimen group S2 was reinforced using one layer of CFRP sheets with 3 replicates, while specimen group S3 was reinforced using two layers of CFRP sheets, also with 3 replicates. The detailed information is listed in table 1.

Tab. 1 Detail Information of Specimen Groups

\begin{tabular}{cccc}
\hline Specimen group No. & Specimen ID & Replicates & Remarks \\
\hline S1 & S1-1 S1-5 & 5 & Control group \\
S2 & S2-1 S2-3 & 3 & Wrapping one layer of CFRP sheets \\
S3 & S3-1 S3-3 & 3 & Wrapping two layers of CFRP
\end{tabular}

Basically, each specimen included glulam members, a steel plate and hex bolts. The glulam member cross-sectional dimensions, $b \times h$, were $130 \mathrm{~mm} \times 305 \mathrm{~mm}$ for the beams and $272 \mathrm{~mm} \times 305 \mathrm{~mm}$ for the columns, respectively. The beam and column lengths were $830 \mathrm{~mm}$ and $1000 \mathrm{~mm}$, respectively. The glulam was made from No.1 visually graded Canadian Spruce-pine-fir dimension lumber. The dimensions of Q390B steel plates (the nominal yielding strength was $390 \mathrm{MPa}$ ) were $745 \times 305 \mathrm{~mm}^{2}$ and $9.5 \mathrm{~mm}$ thick. Low-carbon steel hex bolts were used with a diameter of $20 \mathrm{~mm}$ and a strength grade of 8.8.

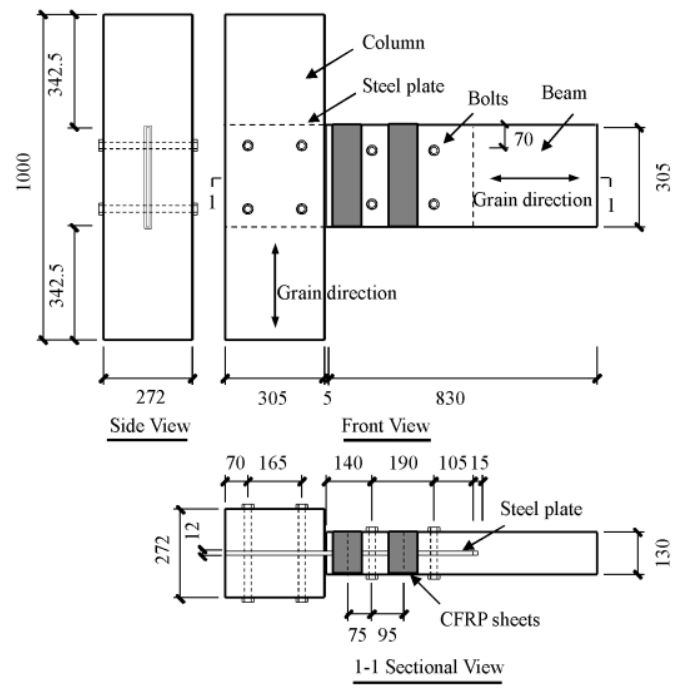

Fig. 1 Details of Specimen Geometry [unit: $\mathrm{mm}$ ]

The Toray unidirectional CFRP sheets and matching glue were used in this study. The tensile modulus and strength of the CFRP sheets measured from material testing were $4501 \mathrm{MPa}$ and $253 \mathrm{GPa}$, respectively. Considering that the failures of unreinforced connections often take place in the end of beam members [1], the CFRP sheets were only wrapped around the potential failure areas.

All the glulam members were predrilled with a tolerance of $2 \mathrm{~mm}$ regarding the bolt diameter for ease of assembly. Then each glulam member was slotted with a width of $12 \mathrm{~mm}$ to accommodate the steel plates. Fig.1 illustrates the detailed layout of the bolts, steel plates and CFRP sheets. 


\section{Testing Device and Measurement Scheme}

The experiments were carried out in the timber testing laboratory of Tongii University. To keep the loading system stable, the specimen was rotated 90 degrees and fixed on the ground before testing. A horizontally arranged hydraulic actuator (with a loading capacity of $300 \mathrm{kN}$ and a stroke range of 250 $\mathrm{mm}$ ) was used to apply a horizontal load on the free end of the beam member with a hinged steel cage. The test specimen and configuration is shown in Fig. 2.

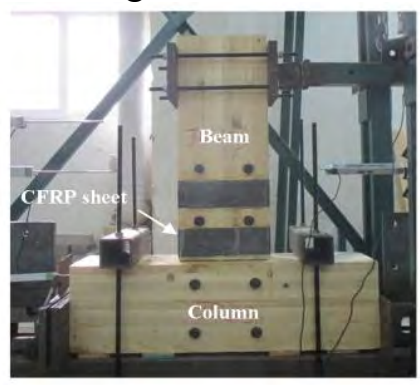

Fig. 2 Test Specimen and Configuration for Bolted Glulam Beam-to-column Connection

The monotonic loading regime was displacement controlled. Its loading rate was set as $10 \mathrm{~mm} / \mathrm{min}$ to be in conformance with previous studies. The specimens were preloaded up to roughly $20 \%$ of the expected maximum load and unloaded to eliminate the influence of the possible loose contact between the bolts and bolt holes. Then the load was increased up to the ultimate failure of the specimen or the stroke range of the actuator was reached.

The applied load was initially measured and recorded by a built-in load dynamometer of the hydraulic actuator and was adjusted when necessary based on the vertical movement of the loading head. The rotational displacements of beam member and steel plate were measured using a series of vertically placed LVDTs, as shown in Fig.3.

Specifically, transducer D1 measured the horizontal displacement of column member; transducers D2 and $\mathrm{D} 3$ were attached to the beam to measure the rotational displacement of the beam with respect to the column $\left(\theta_{\mathrm{BC}}=\left(\mathrm{D}_{2}-\mathrm{D}_{3}\right) / 200\right)$; transducer $\mathrm{D} 4$ was used to record the vertical movement of the actuator; transducers D5 and D6 was attached to the steel plate with a spacing of $190 \mathrm{~mm}$ to measure the rotational displacement of the steel plate with respect to the column $\left(\theta_{\mathrm{SC}}=\left(\mathrm{D}_{5}-\mathrm{D}_{6}\right) / 190\right)$.

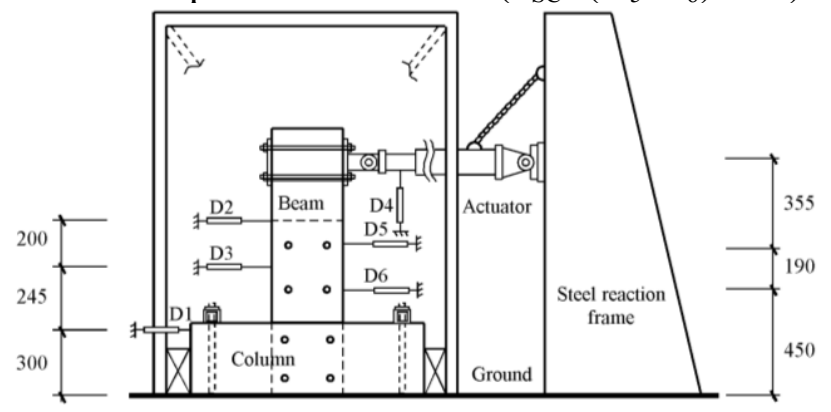

Fig. 3 Data Measurement Scheme [unit: $\mathrm{mm}$ ]

\section{Typical Failure Modes}

\section{Failure Modes of Unreinforced Connections}

When the applied load was up to approximately $5 \mathrm{kN}$, the far end of the beam member pressed column member. When the load was over $26 \mathrm{kN}$ (about $55 \%$ of the maximum load), tensile splitting firstly took place around the bolts at the far side of the beam member, and propagated between the two rows of the bolts and eventually reached the bottom end of the beam. When the load was close to the maximum load, wood plugs under the bolts at the far side of the beam were sheared off. The splitting reached the bottom end and featured the ultimate failure of the connections. 
The glulam beam and column members were cut up after testing for observation of the bolt and bolt-hole deformation pattern. It was founded that the deformation of beam bolts was slight, while significant bending deformation took place in the column bolts. The reason is that the column bolts were roughly 2 times longer and thus slenderer than the beam bolts. Additionally, the column member was fixed tightly on the ground and the far end of the beam member pressed the column member at the end of loading stage, which limited the perpendicular-to-grain tensile stresses in the wood. This was supported by the observation that no noticeable splitting took place in the column members of all the specimens.

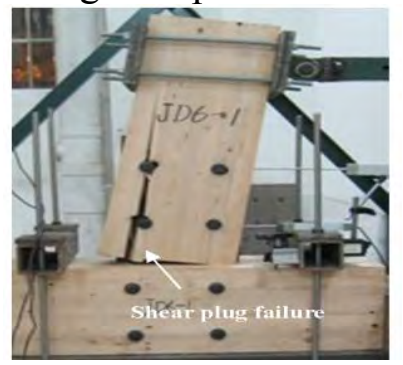

Fig. 4 Damages of Unreinforced Connections

\section{Failure Modes of CFRP-reinforced Connections}

The failure modes of reinforced connections using 1 and 2 layers of CFRP sheets were similar. The beam members and the steel plate rotated together at the initial loading stage due to the bonding between CFRP sheets and the surrounded wood. With load increasing, notable relative rotational deformation occured between the beam and steel plate, causing the debonding failures between CFRP sheets and beam member, as shown in Fig. 5. When the applied load approached to the maximum load, logitudinal shear failures took place around the wood plugs at the far side of the beam member. The bolt squeezed the bottom CFRP sheet and wood plug, which destroyed the bonding between CFRP sheets and glulam member. Meanwhile, tensile splitting took place around the top bolts of the connection. It could be seen that the splitting crack width reduced with the increased layers of CFRP sheets. The reason is that the circumferential confinement of beam member was strengthened significantly from 1 to 2 layers of CFRP sheets.

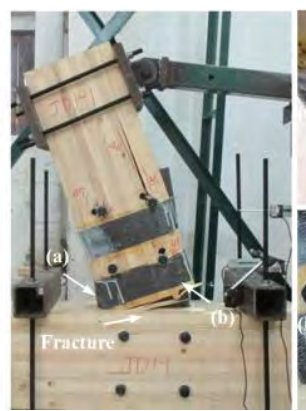

(a) S2-1

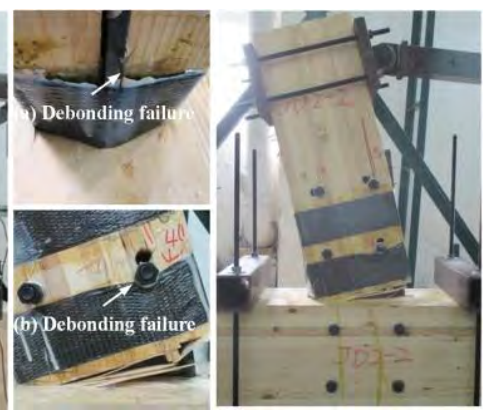

(b) S3-2

Fig. 5 Damages of CFRP-reinforced Connections

\section{Test Results}

The measured force and displacements were used to estalish the relationship between the moments and the corresponding rotational angles. Generally, two methods could be used to calculate the specimen moments: the applied load with respect to the center of rotation of the beam $\left(M_{\text {beam }}\right)$ and the column $\left(M_{\text {column }}\right)$. Three kinds of rotational angles could be calculated: the rotational angles of the beam and steel plate with respect to the column $\left(\theta_{\mathrm{BC}}\right.$ and $\theta_{\mathrm{SC}}$, respectively) and the rotational angles of the beam with respect to the steel plate $\left(\theta_{\mathrm{BS}}\right)$. Three curves of each connection, specifically $M_{\text {column }}-\theta_{\mathrm{BC}}, M_{\text {column }}-\theta_{\mathrm{SC}}$, and $M_{\text {beam }}-\theta_{\mathrm{BS}}$ could be established and the typical curves were shown in Reference [8]. In this study, only the $M_{\text {column }}-\theta_{\mathrm{BC}}$ relationships of the nonreinforced and CFRP-reinforced connections are compared in 
Fig. 6 for brevity, since $M_{\text {column }}-\theta_{\mathrm{BC}}$ curve is widely accepted by researchers and designers, also due to the ease for comparison with previous test results.

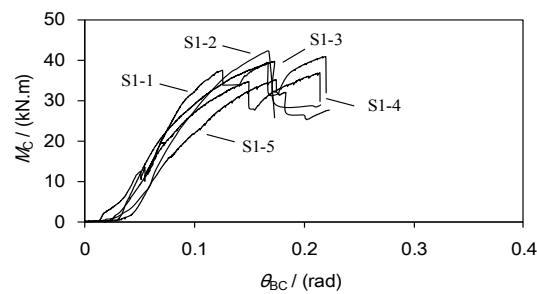

(a) Specimen group S1

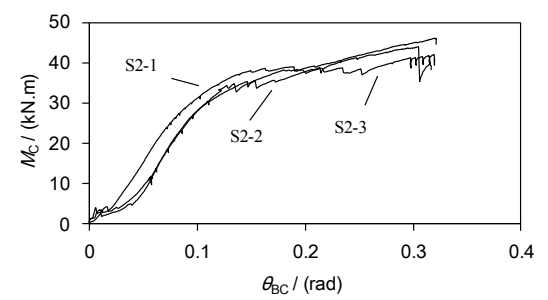

(b) Specimen group S2

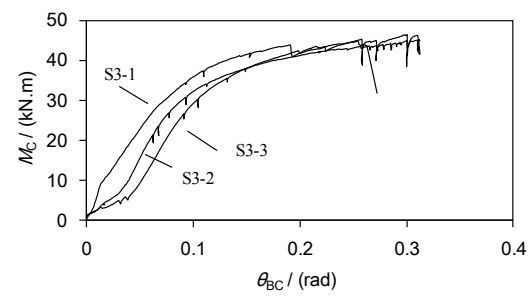

(c) Specimen group S3

Fig. 6 Moment and Rotational Angle Relationships of Each Specimen Group

\section{Discussion}

\section{Moment Resistance of Unreinforced and CFRP-reinforced Connections}

The peak point of the $M_{\text {column }}-\theta_{\mathrm{BC}}$ curve was used to determine the maximum moment of the specimen. Considering the initial slack behavior of the connection, the yielding moments were assessed using a method proposed in previous study [8]: the initial stiffness, $k$, of the $M_{\text {column }}-\theta_{\mathrm{BC}}$ curves was obtained using Eq. 1 , then a tangent line to the nonlinear $M_{\text {column }}-\theta_{\mathrm{BC}}$ curve with a slope of 1/6 of $k$ was set up; and the moment corresponding to the intersection of the tangent line and the initial stiffness line was defined as the yielding moment, $M_{\mathrm{y}}$.

$$
k=\frac{0.4 M_{\text {peak }}-0.2 M_{\text {peak }}}{\theta_{0.4 M_{\text {peak }}}-\theta_{0.2 M_{\text {peak }}}}
$$

The averaged test results of the initial stiffness, yielding moment and maximum moment with corresponding rotatinoal angles are listed in Table 2 for comparison purpose. The initial stiffnesses for CFRP-reinforced connections were slightly lower due to the variation of the tolerance of bolts and bolt holes and elastic modulous of glulam. The maximum moments were increased by $14 \%$ and $18 \%$ for 1 and 2 layers of CFRP-reinforced connections, respectively. It was also found that the variation of the mamxim moment reduced with the CFRP layers increasing.

Tab. 2 Summary of Test Results

\begin{tabular}{|c|c|c|c|c|c|c|}
\hline $\begin{array}{l}\text { Specimen } \\
\text { Group ID }\end{array}$ & $\begin{array}{l}\mathrm{k} \\
{[\mathrm{kN} \cdot \mathrm{m} / \mathrm{rad}]}\end{array}$ & $\begin{array}{l}\text { My } \\
{[\mathrm{kN} . \mathrm{m}]}\end{array}$ & $\begin{array}{l}\theta \mathrm{y} \\
{[\mathrm{rad}]}\end{array}$ & $\begin{array}{l}\text { Mmax } \\
{[\mathrm{kN} . \mathrm{m}]}\end{array}$ & $\begin{array}{l}\theta \max \\
{[\mathrm{rad}]}\end{array}$ & $\beta$ \\
\hline $\mathrm{S} 1$ & $\begin{array}{l}504 \\
(0.21) 1\end{array}$ & $\begin{array}{l}33.9 \\
(0.70)\end{array}$ & $0.103(0.05)$ & $\begin{array}{l}38.4 \\
(0.25)\end{array}$ & $\begin{array}{l}0.182 \\
(0.14)\end{array}$ & $\begin{array}{l}1.8 \\
(0.06)\end{array}$ \\
\hline S2 & $\begin{array}{l}451 \\
(0.09)\end{array}$ & $\begin{array}{l}32.3 \\
(0.05)\end{array}$ & $0.098(0.05)$ & $\begin{array}{l}44.0 \\
(0.09)\end{array}$ & $\begin{array}{l}0.314 \\
(0.01)\end{array}$ & $\begin{array}{l}3.2 \\
(0.03)\end{array}$ \\
\hline S3 & $\begin{array}{l}441 \\
(0.16)\end{array}$ & $\begin{array}{l}35.6 \\
(0.20)\end{array}$ & $0.094(0.13)$ & $\begin{array}{l}45.4 \\
(0.02)\end{array}$ & $\begin{array}{l}0.288 \\
(0.18)\end{array}$ & $\begin{array}{l}3.1 \\
(0.10)\end{array}$ \\
\hline
\end{tabular}

${ }^{1}$ within parentheses are the coefficients of variation.

\section{Deformability of Unreinforced and CFRP-reinforced Connections}

To evaluate the specimen deformability, a deformability ratio, $\beta$, was established in this study and calculated based on the ration of the rotational angle corresponding to the maximum moment, $\theta_{\max }$, to that of the yielding moment of the connection, $\theta_{\mathrm{y}}$. The averaged value of each specimen group is listed in Table 2.

The deformability ratios of reinforced connections wrapped using 1and 2 CFRP sheets were $78 \%$ and $72 \%$ higher than the non-reinforced connections, respectively. The deformability ratios of CFRP-reinforced connections were lower than these of locally cross-laminated connections (3.5, reported by Wang et al. [8]), since the debonding failures prematurely took place between the glulam members and CFRP sheets. 


\section{Summary}

This paper presented the experimental results of the rotational behavior of bolted glulam beam-to-column connections reinforced using CFRP wrapping techniques. The test results indicated that the maximum moments were increased by $14 \%$ and $18 \%$ for connections reinforced using $1 \sim 2$ layers of CFRP sheets, respectively; the deformability ratios based on the rotation angles corresponding to the yielding and maximum moments were $78 \%$ and $72 \%$ higher than non-reinforced connections. It was also found that the variation of moment resistance for reinforced connections reduced with the layers of CFRP sheets increasing.

Future research efforts will be made on different layouts of CFRP sheets to avoid the premature debonding failures between the CFRP sheets and glulam members. Statistic and numerical analysis methods will also be used to establish the relationship between the layers of CFRP sheets and moment resistance improvement.

\section{Acknowledgement}

This research was financially supported by the National Natural Science Foundation of China (Grant No. 51478336).

\section{References}

[1]M.Q. Wang, X.B. Song, X.L. Gu, Y.F. Zhang, L. Luo, Study on rotational behavior of bolted glulam beam-to-column connections with slotted-in steel plates, Journal of Building Structures. 35(9)141-150.

[2]A. Bouchair, J.F. Bocquest, P. Racher, Behavior of moment-resisting connections, Proceedings of the 1996 International Wood Engineering Conference. 2:153-160.

[3]P. Haller, J. Wehsener, T. Birk, Embedding characteristics of fiber reinforced and densified timber joints, Proceedings of CIB W18 Meeting. CIB W18:34-6-12.

[4]B. Kasal, S. Pospisil, I. Jirovsky, A. heiduschke, M. Drdrcky, P. Haller, Seismic performance of laminated timber frames with fiber-reinforced joints, Earthquake Engineering and Structural Dynamics. 33:633-646.

[5]R. Wiktor, Glulam connections using epoxy glued-in rebars, Department of Civil Engineering, University of British Columbia, Vancouver, BC, Canada.

[6]A. Buchanan, P. Moss, N. Wong, Ductile moment-resisting connections in glulam beams, Proceedings of the 2001 NZSEE Conference. Paper no. 6.02.01.

[7]F. Lam, M. Schulte-Wrede, C.C. Yao, J.J. Gu, Moment resistance of bolted timber connections with perpendicular to grain reinforcements, Proceedings of the 2008 World Conference on Timber Engineering.

[8]M.Q. Wang, X.B. Song, X.L. Gu, Y.F. Zhang, L. Luo, Rotational behavior of bolted beam-to-column connections with locally cross-laminated glulam, accepted by Journal of Structure Engineering.

[9]X.B. Song, X.L. Gu, Y.P. Li, T. Chen, W.P. Zhang, Mechanical behavior of FRP-strengthened concrete columns subjected to concentric and eccentric compression loading, Journal of Composites for Construction, ASCE. 17(3):336-346.

[10]W.P. Zhang, X.B. Song, X.L. Gu, H.Y. Tang, Compressive behavior of longitudinally cracked timber columns retrofitted using FRP sheets, Journal of Structure Engineering, ASCE. 138(1)90-98.

[11]K.W. O'Brien, An investigation of FRP reinforced glulam bolted connection, Department of Civil and Environmental Engineering, Columbia University. 